Review

\title{
Non-destructive measurement of chloride ions concentration in concrete - A comparative analysis of limitations and prospects
}

\author{
Yawar Abbas $^{\mathrm{a}, *}$, Farhad Pargar ${ }^{\mathrm{b}}$, Dessi A. Koleva ${ }^{\mathrm{b}}$, Klaas van Breugel ${ }^{\mathrm{b}}$, Wouter Olthuis ${ }^{\mathrm{a}}$, \\ Albert van den Berg ${ }^{a}$ \\ a BIOS-Lab on a Chip Group, MESA+ Institute of Nanotechnology, MIRA Biomedical Technology and Technical Medicine, University of Twente, 7500AE Enschede, The Netherlands \\ ${ }^{\mathrm{b}}$ Faculty of Civil Engineering and Geosciences, Materials and Environment, Delft University of Technology, Stevinweg 1, 2628CN Delft, The Netherlands
}

\section{H I G H L I G H T S}

- Measuring chloride is crucial for service life assessment of concrete structures.

- Measurement techniques mainly based on electrochemistry and electromagnetics.

- Based on the level of assessment different techniques have pro and cons.

- For existing structure assessment varies from visual to detailed lab investigation.

- Electrochemical sensor are suitable for installation in new structures.

\section{A R T I C L E I N F O}

\section{Article history:}

Received 14 January 2018

Received in revised form 8 April 2018

Accepted 15 April 2018

\section{Keywords:}

Reinforced concrete

Chloride ingress

Chloride measurement

Durability

Non-destructive techniques

\begin{abstract}
A B S T R A C T
In this work, the different techniques for non-destructive in situ measurement of chloride ion concentration are presented. Non-destructive (ND) in situ measurement is crucial for reliable and continuous determination of chloride ion concentration in concrete. Over the last 20 years, several studies have been performed on ND measurements. These were mainly focused on the application of electrochemical and electromagnetic techniques. Each technique has its advantages and disadvantages. Depending on the requirement of assets managers and constructors and considering the limitations, these techniques can be well applied. The main concepts and comparative analysis, in view of possibilities and limitations, of these non-destructive techniques are presented in this paper.
\end{abstract}

(c) 2018 Elsevier Ltd. All rights reserved.

\section{Contents}

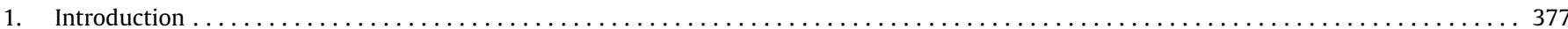

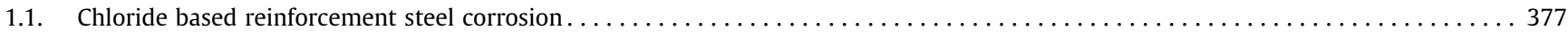

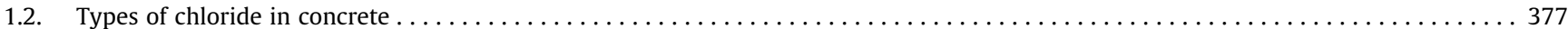

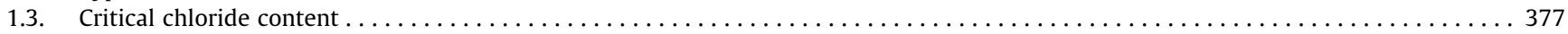

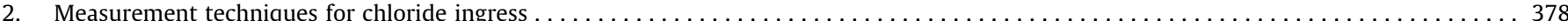

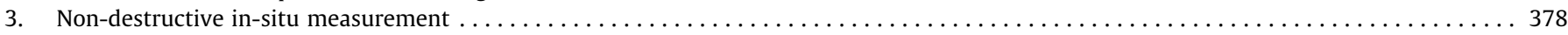

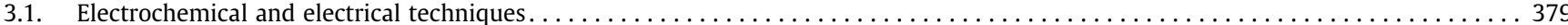

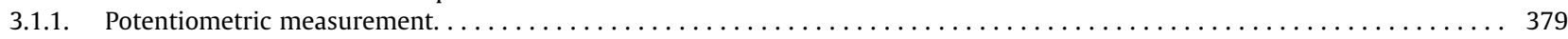

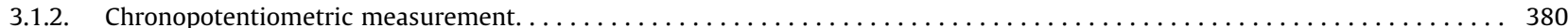

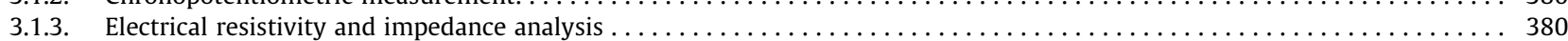

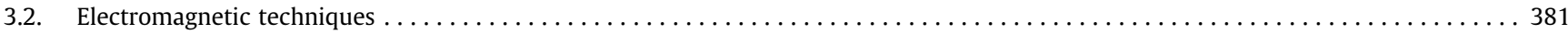

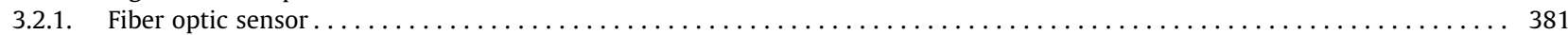

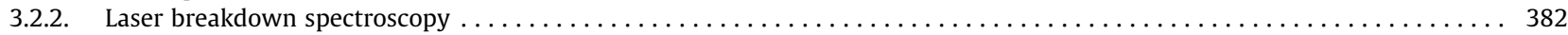

\footnotetext{
* Corresponding author at: University of Twente, ZH 111, PO Box 217, 7500AE Enschede, The Netherlands.

E-mail addresses: Y.Abbas@utwente.nl (Y. Abbas), F.Pargar@tudelft.nl (F. Pargar), D.A.Koleva@tudelft.nl (D.A. Koleva), K.vanBreugel@tudelft.nl (K. van Breugel), W.Olthuis@utwente.nl (W. Olthuis), A.vandenBerg@utwente.nl (A. van den Berg).
} 


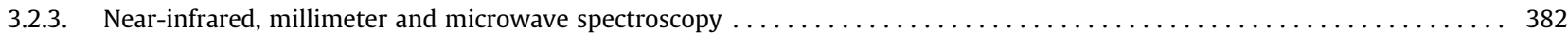

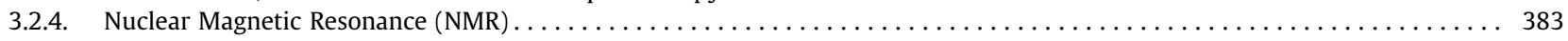

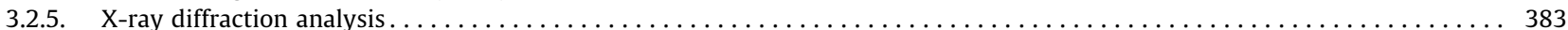

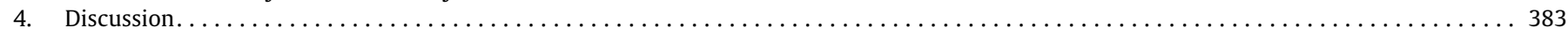

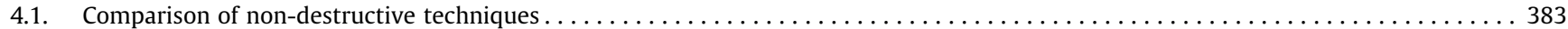

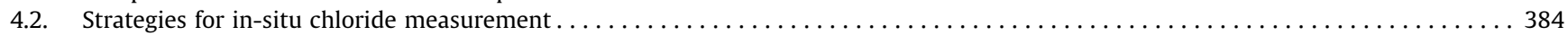

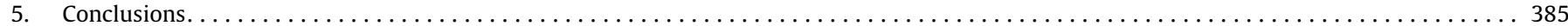

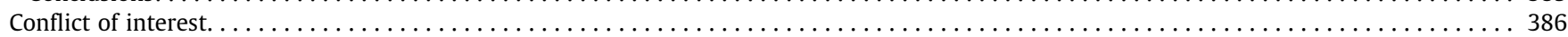

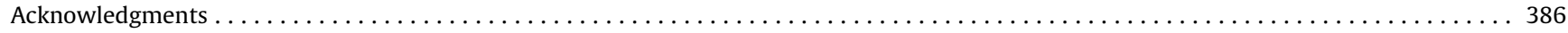

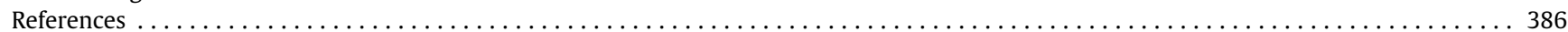

\section{Introduction}

\subsection{Chloride based reinforcement steel corrosion}

The concentration of chloride ions is one of the most important indicators for the deterioration of reinforced concrete (RC) structures [1-6]. In the presence of a critical amount of chloride ions, also known as critical chloride content, the reinforcing steel undergoes rapid localized corrosion. Such localized corrosion can form "pits", giving rise to the term localized corrosion [7-9]. Although localized corrosion might not have a significant immediate consequence for the daily operation of a reinforced concrete structure, it may affect the structural performance of the concrete structure in the long term and under specific load or environmental conditions, such as earthquakes $[10,11]$. Corrosion drastically reduces the tensile strength of steel, and thus compromises the load bearing capacity of reinforced concrete. During corrosion, the passive film of iron oxide, initially formed on the surface of steel and inhibiting further corrosion, is destroyed. In case of chloride induced corrosion, this passive film is locally broken. The on-going corrosion process results in the formation of voluminous corrosion products. This results in early crack formation, propagation and possible detachment of the concrete cover. Structures near marine environment or those exposed to de-icing salts are prone to pitting corrosion. Specially, the splash zone near seawater, which is the area near the air/water interface, undergoes such deterioration, due to readily available atmospheric oxygen, water, and chloride [12-14]. On-demand maintenance of these structures not only preserves them but also reduces unnecessary costs and energy [15]. The chloride ion concentration in concrete is one of the most relevant parameters to estimate the risk of corrosion, and therefore predict the lifetime and maintenance cycle of RC structures [16-19].

In the present review, different techniques are summarized, reported so far for non-destructive in-situ measurement of chloride ion concentration in concrete. For more than two decades in-situ non-destructive measurement of chloride content in concrete has been reported in literature [20-22]. These ND techniques are characterized into two main approaches, i.e. electrochemical and electromagnetic. The description of these techniques along with their advantages and disadvantages are presented. In concrete, chlorides exists in different forms, namely free and bound chloride. Before describing the measurement techniques, it is important to introduce the states of the chloride ions in cementitious materials.

\subsection{Types of chloride in concrete}

Free chloride exists in ionic form in the pore solution and can diffuse towards the reinforcing steel through the pores. The traditional methods for free chloride ions determination involve extracting the pore solution from the cement-based materials by applying pressure, or by leaching of chloride from the concrete sample by a solvent. It has been stated that these techniques are prone to considerable error. For example, destructive extraction of pore solution may overestimate the free chloride concentration by $30 \%$ to $200 \%$ [23].

The bound chloride ions are either chemically or physically attached to the hydration product such as calcium-silicatehydrate (C-S-H) [24]. The chloride adsorption on the surface of C$\mathrm{S}-\mathrm{H}$ gives the physical binding of the chloride. It is due to electrostatic or Van der Waals forces between the chloride ions and the surface of the C-S-H. Such chloride ions are sensitive to the environmental conditions such as pressure and temperature. Chemical binding is the result of chemical reactions between chloride ions and cement hydration products such as tri-calcium aluminate $\left(\mathrm{C}_{3} \mathrm{~A}\right)$ to form calcium chloroaluminate hydrate or Friedel's salt [25]. However, Friedel's salt is not the only phase responsible for chloride binding [26], other phases including Calcium-SilicateHydrate $(\mathrm{C}-\mathrm{S}-\mathrm{H})$, hydration product of alite $\left(\mathrm{C}_{3} \mathrm{~S}\right)$ and belite $\left(\mathrm{C}_{2} \mathrm{~S}\right)$, $[27,28]$ and the ferrite analogue of Friedel's salt also account for chloride binding [29-31]. The chemically bound chloride can be extracted in acidic environment [23,32].

\subsection{Critical chloride content}

Localized, or pitting corrosion in RC is initiated when the chloride ion concentration reaches a threshold value, which is also known as the critical chloride content, $C_{\text {crit }}[33,34]$. There are two different ways of defining $C_{\text {crit }}$ : (1) based on theory i.e. the chloride ion concentration required for de-passivation of steel, (2) based on the visible deterioration of the concrete structure [34]. There are two stages of deterioration due to corrosion; initiation and propagation stage. In the initiation phase, no significant deterioration is observed, whereas in the propagation stage large deterioration and increase in corrosion rates are observed. According to the first definition the amount of chloride to initiate the propagation stage is $C_{\text {crit }}$, whereas, according to the second definition the amount of chloride to observe the visible deterioration in the propagation stage is $C_{\text {crit }}$.

Regarding the type of chloride responsible for pitting corrosion, some literature reports consider total chloride content $[35,36]$ and others free chloride [34,37]. The free chloride ion concentration is mostly reported to be a better indicator for pitting corrosion. Several studies have been performed to evaluate $C_{c r i t}$ [34], but there is no universal value so far, since it depends on several factors like $\mathrm{pH}$, temperature, humidity, oxygen availability and steel concrete interface $[34,38]$.The heterogeneity of the concrete matrix can also affect the measurements. Angst et al. 2009 reviewed several conditions and mentioned values for critical chloride content reported so far [34]. According to this study, the ratio between the $\left[\mathrm{Cl}^{-}\right]$ and $\left[\mathrm{OH}^{-}\right]$is found to be an appropriate expression form of $C_{\text {crit }}$, with the most accepted value of $\left[\mathrm{Cl}^{-}\right] /\left[\mathrm{OH}^{-}\right]=0.6$. 


\section{Measurement techniques for chloride ingress}

There are different approaches to measure chloride ion concentration in concrete depending on the application, i.e. determining the chloride ingress profile for quality control of new structures or chloride ion concentration in existing structures. The most routinely used technique is the leaching method and subsequently analysis of the extracted solution using potentiometry and the Volhard method, so measuring the free and total chloride content, respectively [39]. An overview of the available techniques is shown in Fig. 1.

The techniques are broadly categorized into laboratory and field methods. The laboratory methods are used to validate the concrete-chloride penetration models and the quality of concrete beforehand. These techniques are mainly focused on determination of the diffusion coefficient and the ingress profile of chloride over time. These studies use different description and theories such as Fick's law, Nernst-Planck equation [40], binding isotherms [6], moisture transport [17] and temperature variation [39,41]. On the other hand, the field methods are focused on measuring chloride in existing concrete for determining its durability and maintenance cycle.

The field methods are further divided into destructive and nondestructive measurements. The state-of-the-art Volhard [42-44] and potentiometric analysis methods $[21,35,45,46]$ are both destructive and require extracted pore solution. These analyses are based on leaching [47]and pore solution expression [48] techniques of sampling. Such destructive sampling can result in significant measurement errors due to the concrete heterogeneity and the sample preparation [49], resulting in under or overestimations. Furthermore, such destructive approaches bring additional indirect costs due to road closures and traffic delays $[15,39]$.
These techniques are mostly used for short-term decisions regarding maintenance and model updating [16,39,50].

The non-destructive methods are characterized by their noninvasive nature. These techniques work by either using external contactless measurement or embedded sensors inside concrete [39,51]. The non-destructive methods are mainly divided into electrochemical and electromagnetic approaches. Although some of the electromagnetic approaches seem destructive and laborious, such as Nuclear Magnetic Resonance (NMR), X-ray and Prompt Gamma Neutron Activation (PGNA) analysis, these methods have potential for non-invasive measurements. Therefore, they are categorized as non-destructive techniques in this review. The focus of this review is on the non-destructive measurement techniques, which are indicated in the red-dotted boxes in Fig. 1.

\section{Non-destructive in-situ measurement}

Non-destructive (ND) measurement of chloride ions in concrete is not a straightforward task. A perfect method must obey several conditions: it must be stable, non-invasive, invariant to chemical and thermal changes in concrete, able to pass small currents with a minimum of polarization and hysteresis effects (for electrochemical methods), display long-term performance, cost effective and result from an environmentally safe manufacturing procedure [52]. Concrete is a heterogeneous material with perm-selective properties of pore walls of cement hydration products, high alkaline pore solution with different compositions and pore systems with various porosity and pore size distribution [53,54]. These properties induce challenges for the available chloride measurement techniques. Many attempts have been made to describe and overcome the limitations for application of these techniques in the concrete environment. These efforts are discussed in the following sections.

\section{Measurement techniques for chloride ion concentration in concrete}

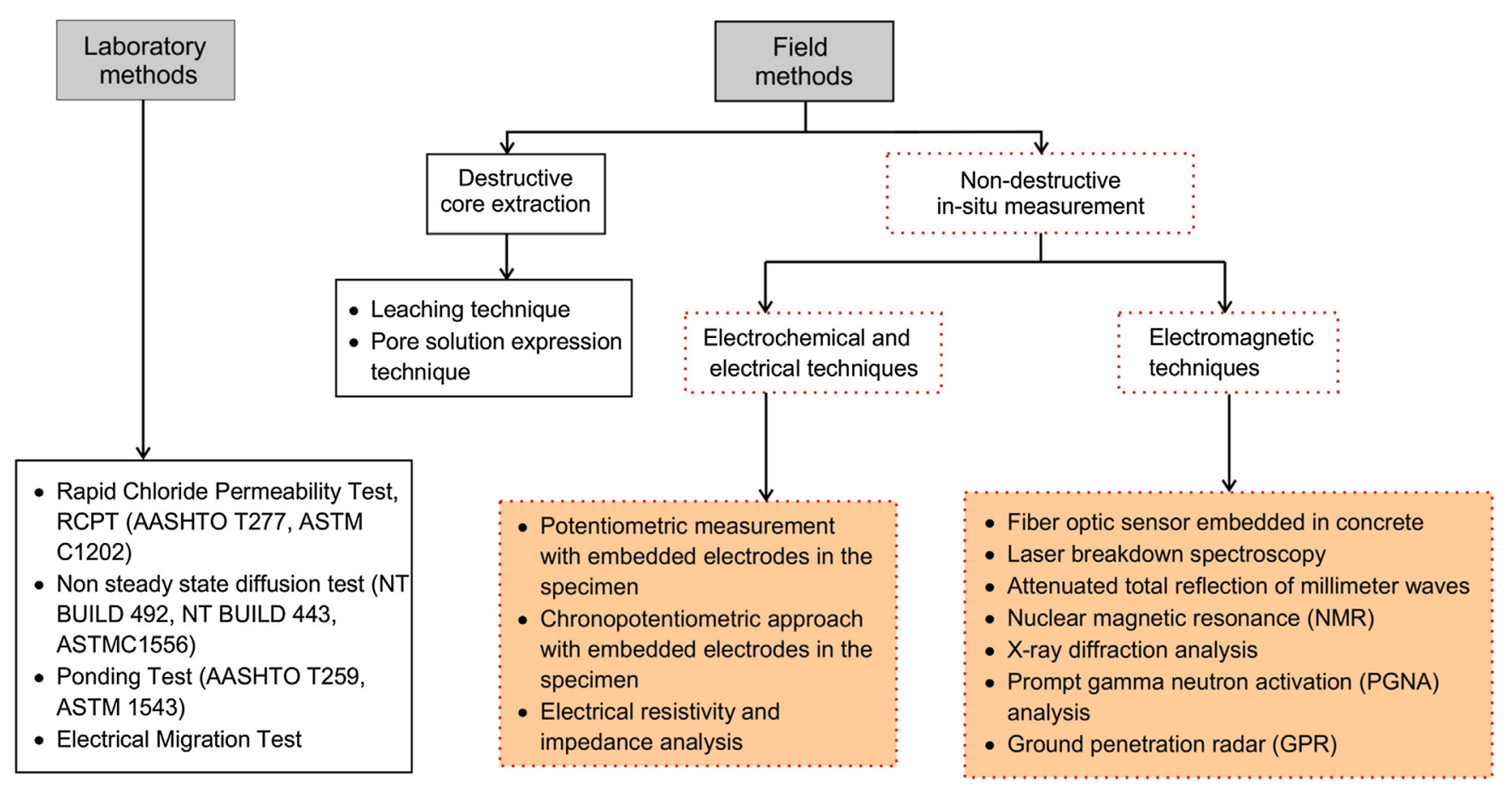

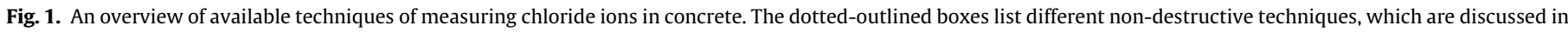
this work. 
(a)

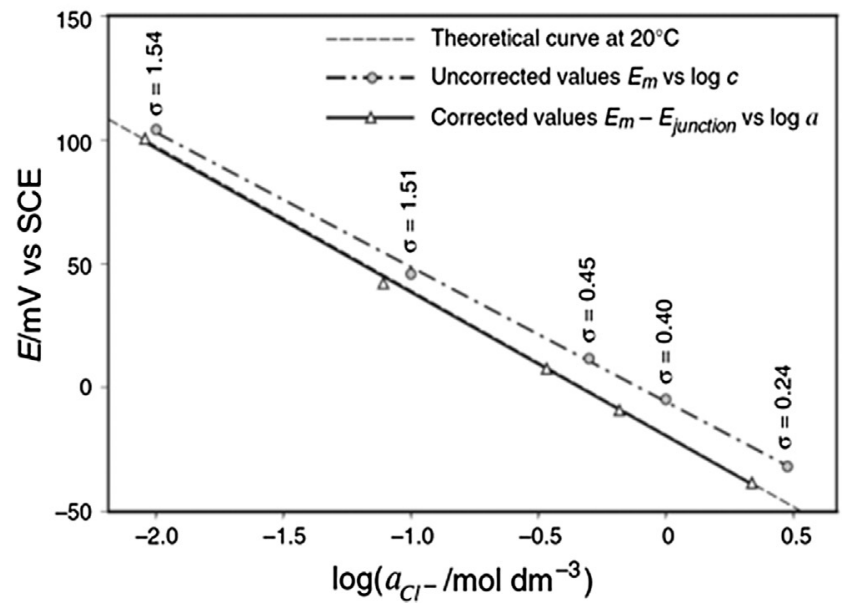

(b)

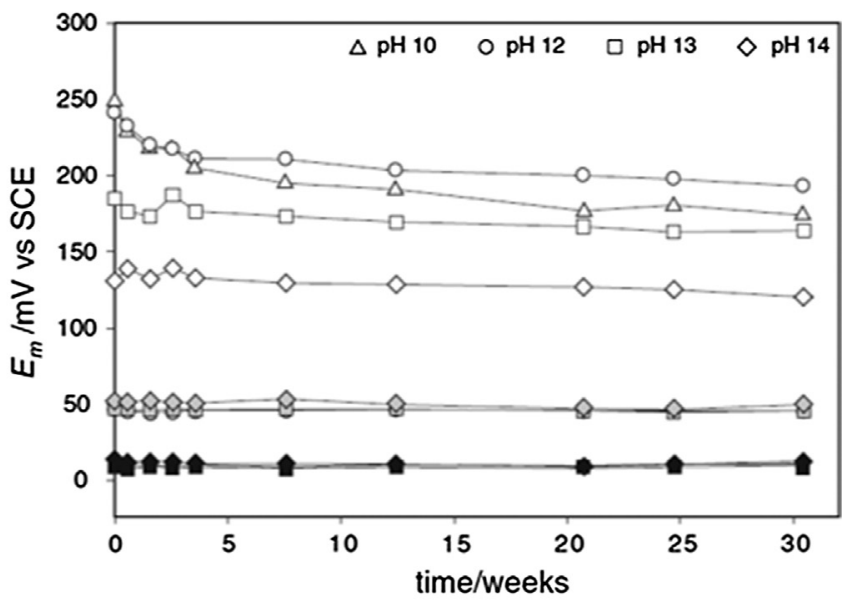

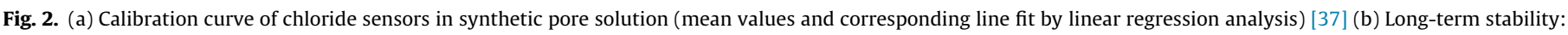

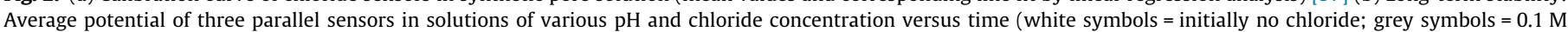
$\mathrm{NaCl}$; dark symbols $=0.5 \mathrm{M} \mathrm{NaCl}$ ) [37].

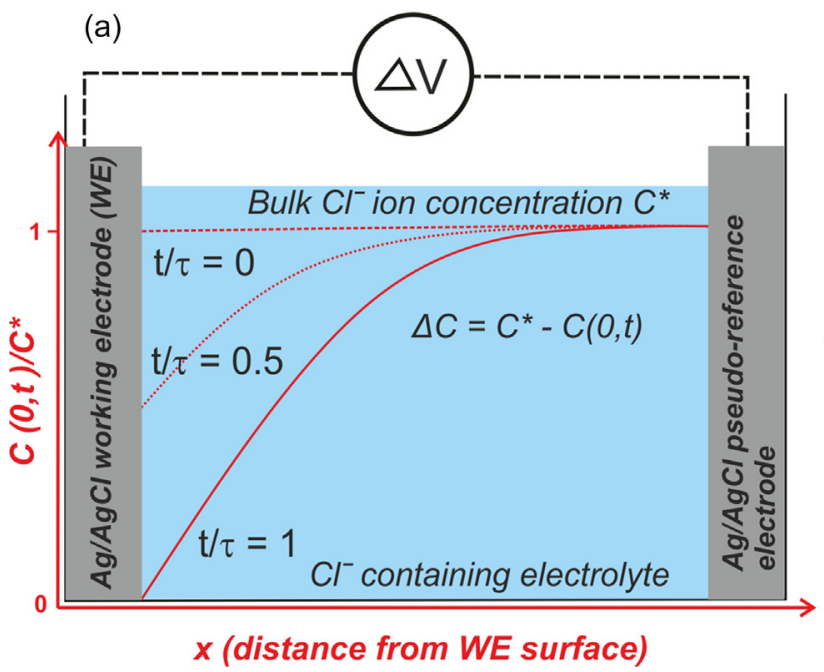

(b)

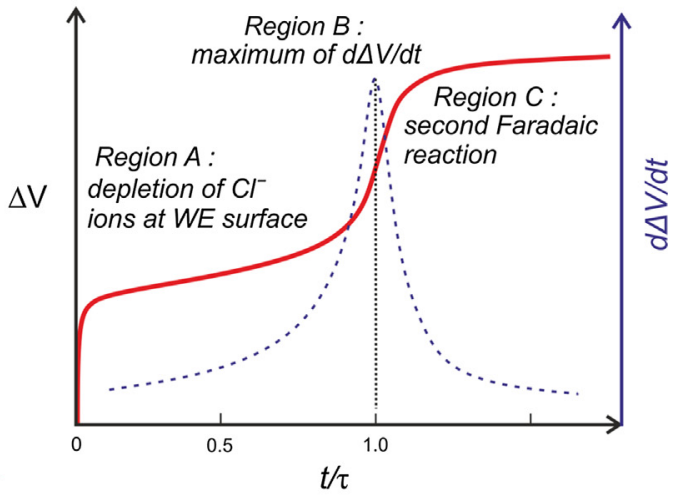

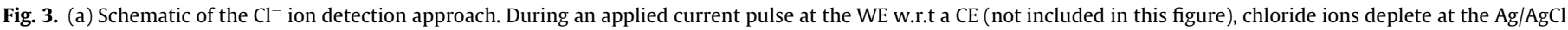

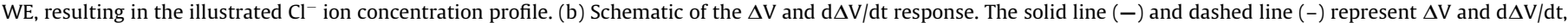
respectively. $\tau$ is the transition time and $t$ is the duration of the applied current pulse [58].

\subsection{Electrochemical and electrical techniques}

\subsubsection{Potentiometric measurement}

Potentiometric measurement, using a $\mathrm{Ag} / \mathrm{AgCl}$ chloride ion selective electrode, is a standard electrochemical technique to measure free chloride concentration in concrete $[20,21,37,51,52,55]$. For concrete applications, the first attempt to use embedded $\mathrm{Ag} / \mathrm{AgCl}$ electrodes was done in the 1990s [20,21,51,56,57]. The $\mathrm{Ag} / \mathrm{AgCl}$ electrode is a chloride ion selective electrode (ISE) whose half-cell potential is a function of the $\mathrm{Cl}^{-}$concentration [37]. The change in half-cell potential is measured against a reference electrode to correlate it to the chloride ion concentration. Calculations and interpretation follow the Nernst equation and behavior [37]. The calibration curve of the potential difference of the $\mathrm{Ag}$./ $\mathrm{AgCl}$ electrode with respect to a $\mathrm{Ag} / \mathrm{AgCl}$ liquid junction reference electrode for various $\mathrm{Cl}^{-}$concentrations, along with the standard deviation, $\sigma$, in synthetic pore solution, reported by Angst et al. , is shown in Fig. 2a [37]. The uncorrected values curve is the measured potential response, which is then adjusted for the activity coefficient to give the corrected values curve.

For field but also in lab applications, the $\mathrm{Ag} / \mathrm{AgCl}$ electrode can be embedded (cast-in)in concrete and its potential can be measured with respect to an external (or internal) reference electrode. Angst et al. reported the half-cell potential of an embedded $\mathrm{Ag} / \mathrm{AgCl}$ electrode over a period of one month for 0.1 and $0.5 \mathrm{M} \mathrm{Cl}^{-}$concentration in various alkaline media, results shown in Fig. 2b [38]. The reference electrode was externally positioned. For electrical contact during the measurements, the reference electrode used a liquid junction (soaked sponge in this case). In the absence of chloride, the potential changes are due to high $\mathrm{pH}(\mathrm{pH}>10)$, whereas at high chloride ion concentration $(0.5 \mathrm{M})$, the half-cell potential is not sensitive to the $\mathrm{pH}$ change and predominantly reflects the activity of chloride ions. The sensitivity toward hydroxide ions is due to the formation of silver-oxide through a redox reaction at the higher $\mathrm{pH}$ concentration $[37,58]$. 
(a)

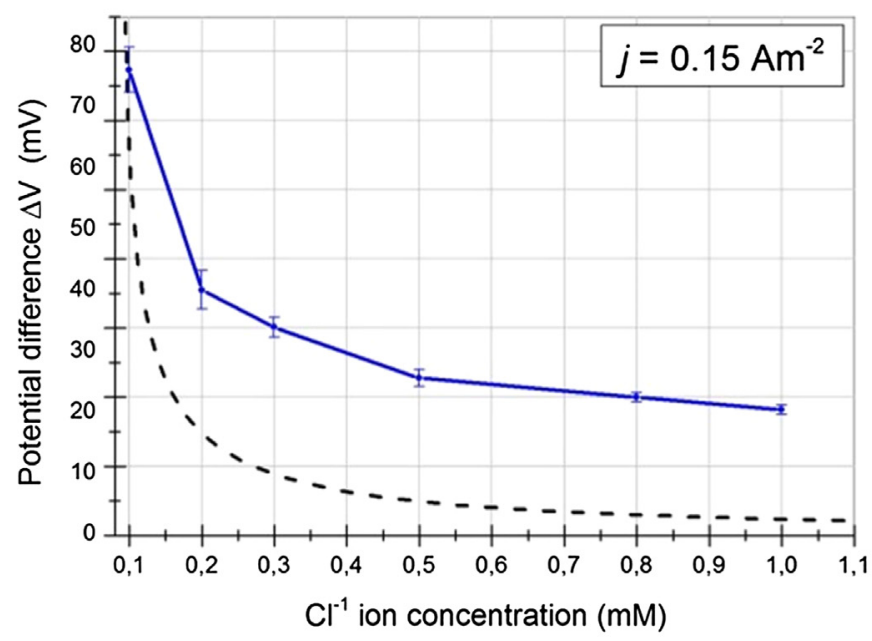

(b)

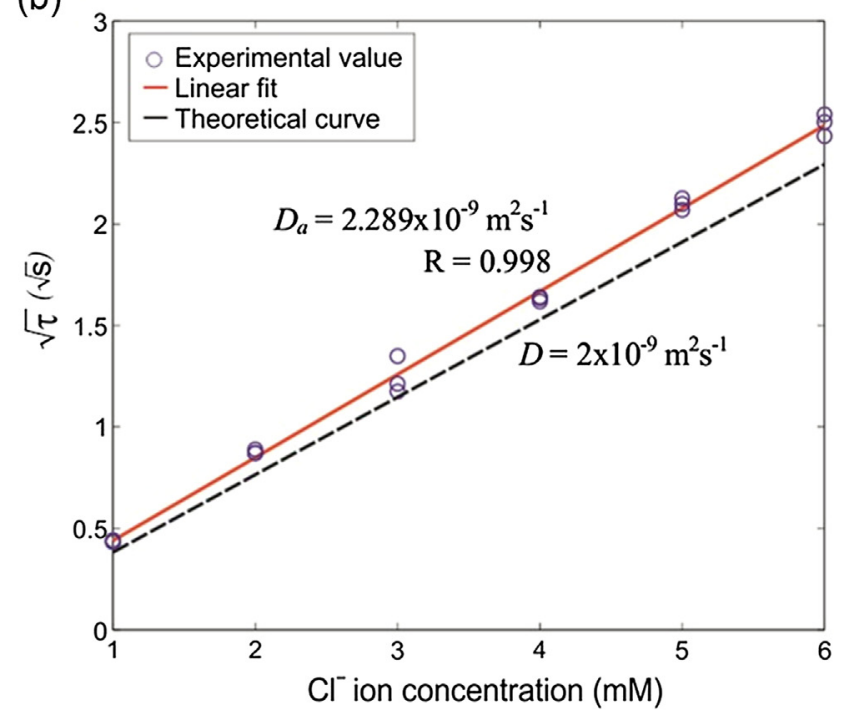

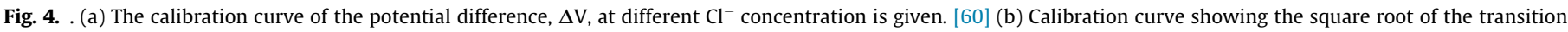

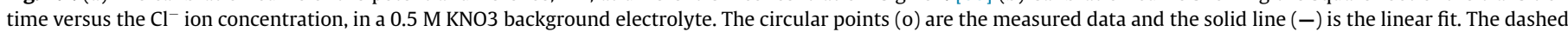

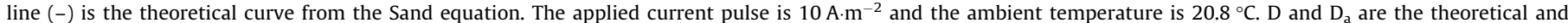
apparent (measured) diffusion coefficients, respectively [58].

Although, this technique is simple and easy to implement, it is prone to error, mostly, coming from the drift in potential of both $\mathrm{Ag} / \mathrm{AgCl}$ electrodes (the chloride sensors) and reference cells. The theoretical sensitivity of this technique is $-59 \mathrm{mV} /$ [decade change in chloride ion concentration], which means a change of $8.9 \mathrm{mV}$ or a two-fold error in the determination of chloride ions concentration [59]. Therefore, for a reliable measurement, a long-term ( $>10$ years) stable reference electrode is to be used.

\subsubsection{Chronopotentiometric measurement}

An alternative for the classical potentiometry is chronopotentiometry; a dynamic electrochemical method where the response of the system is measured to an applied stimulus. Abbas et al. reported this approach to counteract the drift issues in potentiometric response $[58,60]$. In this technique, the potential difference is measured between two $\mathrm{Ag} / \mathrm{AgCl}$ electrodes, one being the working (WE) and the other as a reference electrode (RE), whilst a current pulse is applied to the $\mathrm{WE}$.

When a current pulse is applied to the $\mathrm{Ag} / \mathrm{AgCl}$ working electrode, its potential changes as a function of the $\mathrm{Cl}^{-}$concentration in the electrolyte. The schematic of this process is shown in Fig. 3 [58]. The $\mathrm{Cl}^{-}$is consumed during the applied current pulse due to the Faradaic reaction $\left(\mathrm{Ag}+\mathrm{Cl}^{-} \rightarrow \mathrm{AgCl}\right)$. This change in concentration changes the half-cell potential of the $\mathrm{Ag} / \mathrm{AgCl}$ working electrode, region $\mathrm{A}$ in Fig. 3. After some time, the $\mathrm{Cl}^{-}$will be depleted completely near the surface of the $\mathrm{Ag} / \mathrm{AgCl}$ electrode, resulting in a sharp increase in its potential. This moment is called transition time, given by the Sand equation [61], region B in Fig. 3. Therefore, the $\mathrm{Cl}^{-}$concentration can be measured, either by measuring the potential change (Differential potential) in region $\mathrm{A}$ [60] or by measuring the transition time in region $B$ [58]. This measurement over a long-time period did not show any drifts in potential as reported by Abbas et al. [58]. However, at higher $\mathrm{pH}(>\mathrm{pH}$ 12) the response is no more a function of chloride ions due to the interference of $\mathrm{OH}^{-}$at higher $\mathrm{pH}$, as aforementioned.

The calibration curves obtained from both chronopotentiometric approaches, i.e. measuring differential potential (region A) and transition time (region B), are shown in Fig. 4a and b. In Fig. 4a, the potential change, $\Delta V$, decreases with the increase in $\mathrm{Cl}^{-}$concentration [60]. Fig. $4 \mathrm{~b}$ shows that the transition time increases with the increase in $\mathrm{Cl}^{-}$concentration [58].

\subsubsection{Electrical resistivity and impedance analysis}

The electrical resistivity (ER) is a measure of the ionic and moisture content of a concrete sample [62-64]. In an ER measurement, a potential $(\mathrm{V})$ is applied between two electrodes and the current (I) is measured. From this, the electrical resistance and resistivity can be computed. An increase in chloride ion concentration in concrete decreases its resistivity, if other factors remain constant [64$66]$ and given that chloride binding does not lead to microstructural changes, matrix densification and/or connected pore network alterations.

This method is used mainly to determine the diffusivity of $\mathrm{Cl}^{-}$in concrete. The diffusion coefficient is related to electrical resistivity via the Nernst-Einstein equation [67]. Ozkan [68] measured the diffusion coefficient of $\mathrm{Cl}^{-}$using ER measurements. The experimental setup and the measurement results are shown in Fig. 5 [68]. In Fig. 5a, the concrete sample is placed between two embedded electrodes and a dc potential is applied. The resistivity is obtained according to the standard ASTM C1760 method, which is calculated based on Ohm's law. In Fig. 5b, the measured relationship between the chloride diffusivity and the electrical resistivity is shown. This shows an exponential relation between the resistivity of concrete and the diffusivity of $\mathrm{Cl}^{-}$[68].

The ER measurements give the resistive behavior of concrete. Impedance analysis, on the other hand, utilizes both the resistive and capacitive changes in concrete due to chloride ingress. An alternating current is applied to an electrode with a range of frequency sweeps and the (complex) impedance is evaluated. The curve is then compared with an equivalent electrical model of the electrode in concrete, keeping other parameters constant, and the chloride profiles are then calculated $[69,70]$. The lack of selectivity toward chloride ions, limits this technique for reliable measurement of chloride ion in the field. This is because it is difficult to keep other ambient factors such as temperature, moisture, $\mathrm{pH}$ and other ionic composition constant. 
(a)

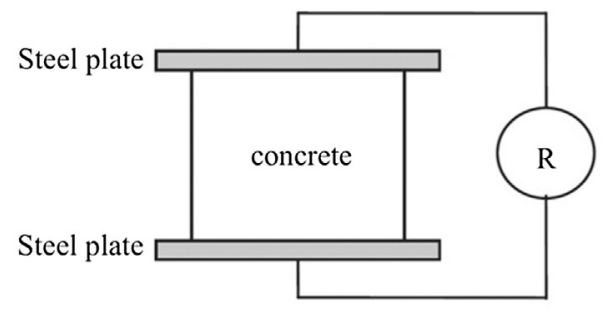

(b)

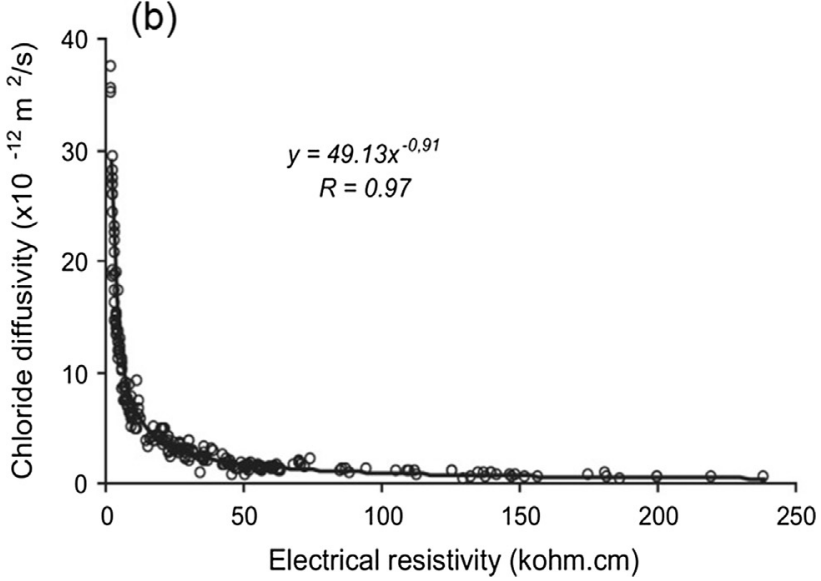

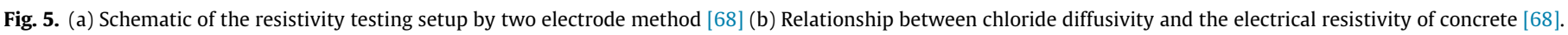

\subsection{Electromagnetic techniques}

\subsubsection{Fiber optic sensor}

Embedded fiber optic chloride sensors allow a non-destructive manner of determining the $\mathrm{Cl}^{-}$content, along with $\mathrm{Cl}^{-}$penetration into concrete structures [71-74]. Over the last decade, several groups have developed fiber optic sensors to measure the free chloride content in concrete. The principle is based on changing the optical properties of an opto-chemical transducer as a function of the $\mathrm{Cl}^{-}$concentration. The fiber optic sensors have three critical parts: (1) Opto-chemical transducers (2) optical signal carrier (3) light source and spectrometer. Generally, optical fibers are used as signal carriers. The standard light sources and spectrometers are commercially available. Fiber optic sensors offer several advantages when compared to electrochemical techniques, such as better stability against interfering ions, sensitivity and inertness to electromagnetic noise and electrical cross-talk [71]. However, in the long-term, fiber material degradation, the necessity of protection of the transducing element in aggressive environment, mechanical stability and temperature dependence are some critical issues, which should be solved. Mostly, research has been done on the opto-chemical transducing part as it defines the sensitivity, selectivity, and long-term performance of the sensor [74-77]. There are two approaches for opto-chemical transduction: (a) fluorescence-based and (b) optical grating (refractive index) based. These are briefly discussed below.

\section{(a) Fluorescence-based optical sensors}

This sensing mechanism is based on the collisional quenching of the fluorescence molecule by chloride ions [77]. Such an optochemical transducer is also referred to as an optode. The determination of the concentration with opto-chemical probes is made possible by recent developments of fluorophores. Collisional quenching is a reversible process where the emitted intensity of fluorescence molecules decrease nonlinearly with increasing quencher concentration, in this case chloride ions.

\section{(b) Optical grating}

The optical grating sensor is based on the modification of the grating portion of a long-period fiber grating (LPG). This sensor is (a)

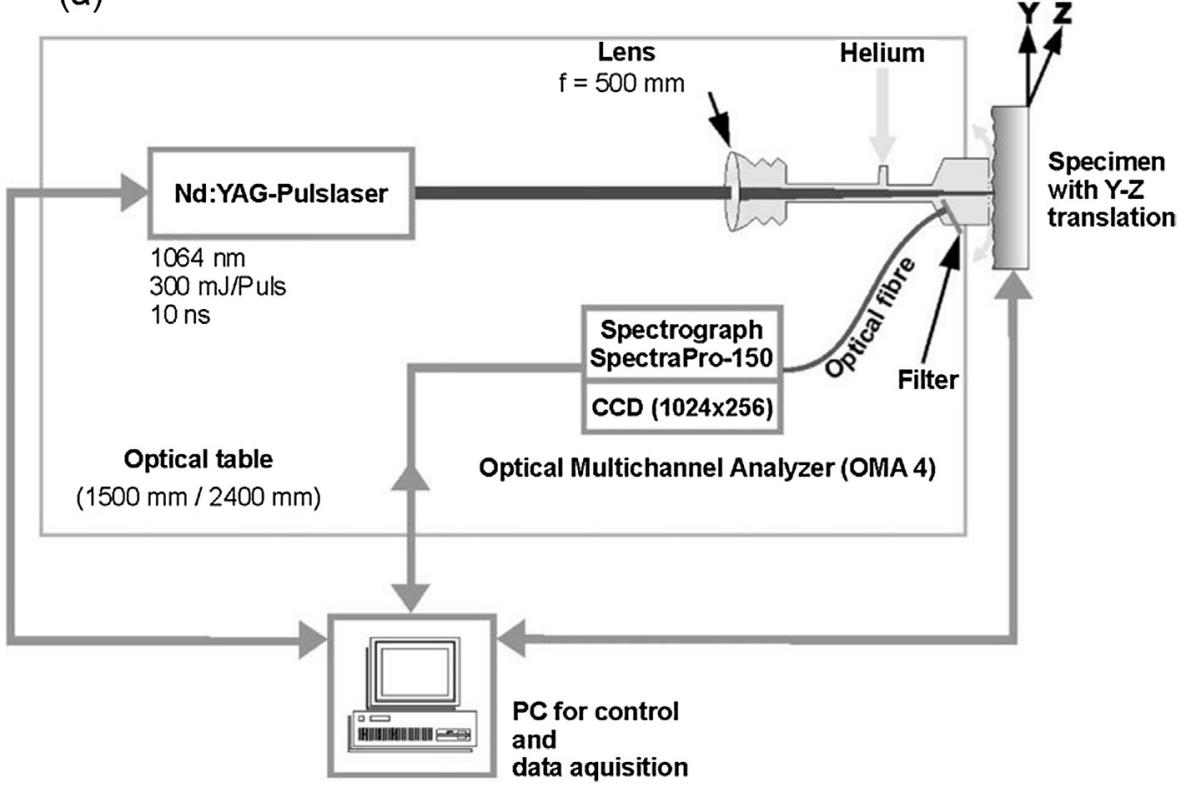

(b)

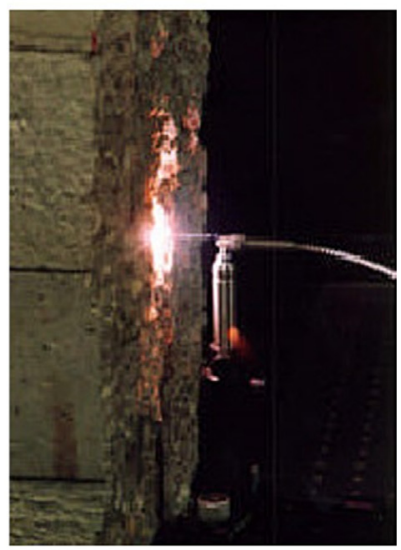

Fig. 6. (a) Experimental setup of LIBS technique [79]. (b) A snapshot of the plasma on the surface of a building material during LIBS measurement [84]. 


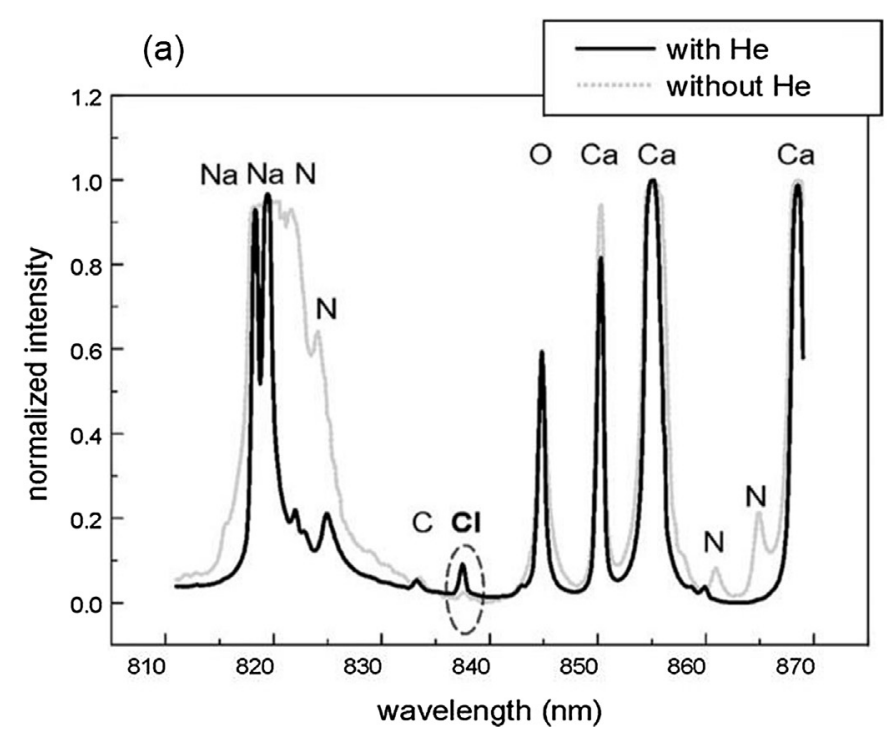

(b)

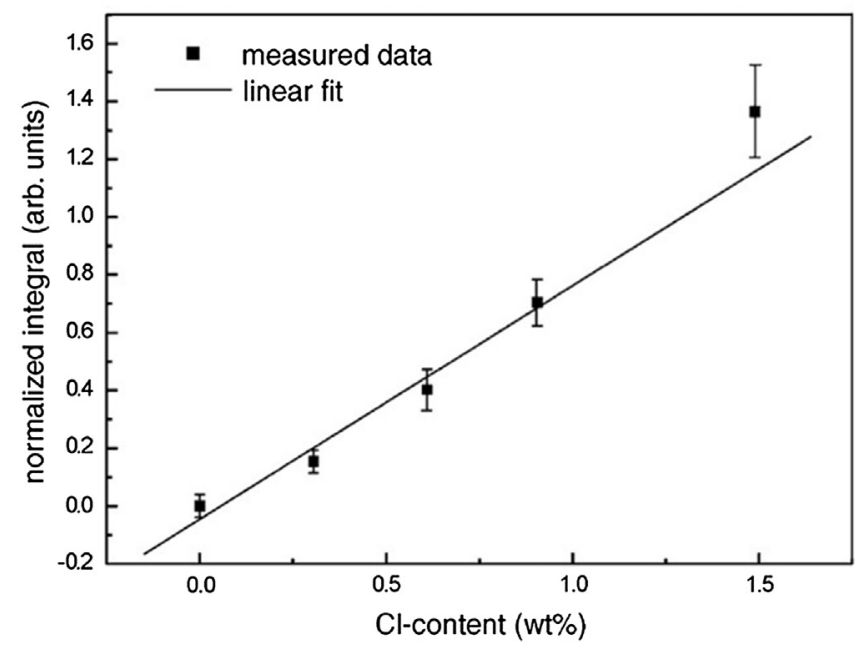

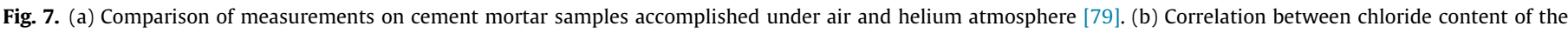
cement mortar samples and normalized integral of $\mathrm{Cl}$ spectral line [79].

extremely sensitive to any changes in Refractive Index (RI) of the grating surrounding. The selectivity toward chloride is enhanced by incorporating a monolayer of self-assembled gold colloids with the LPG [78]. Tang and Wang 2007 [73] used this approach to measure chloride ion concentration in concrete.

\subsubsection{Laser breakdown spectroscopy}

This method is able to detect the total chloride content in a concrete sample. Laser-induced breakdown spectroscopy (LIBS) allows the measurement of elements on the surface of solids, liquids, and gases. In this technique, first a laser pulse evaporates a small amount of elements from the surface forming plasma plume. This plasma radiation is then analyzed through spectroscopic technique to detect its composition [79-83].

The LIBS setup to measure chloride in concrete samples is shown in Fig. 6. A high-energy Laser beam (Nd-YAG laser, pulse duration 10 ns, energy $300 \mathrm{~mJ} /$ pulse) is focused on the sample through a lens. The high energy density $\left(>2 \mathrm{GW} / \mathrm{cm}^{2}\right.$ ) produced plasma with the evaporation of a small amount of the sample. The relaxation spectra of the atomic emission is observed at the detector. The optical signal is directed through a fiber optic cable to the detector. Due to other contamination from building material, the spectral peak of chloride is weak, which can be enhanced by flushing the sample with helium gas. The atomic emission spectrum of a concrete sample with and without helium flushing is shown in Fig. 7a. The chloride spectral line at $837.6 \mathrm{~nm}$ is reported to have repeated peaks. The integral of the chlorine spectra gives the content of total chloride, which is the measured response for calculating chloride ion concentration. The calibration curve of the normalized response at various chloride contents is shown in Fig. 7b. The response increases with the increase in chloride ions in the sample.

\subsubsection{Near-infrared, millimeter and microwave spectroscopy}

The electromagnetic waves below the $\mathrm{THz}$ frequency range (near infrared, micro and millimeter wave) are known to have higher penetration and spatial resolution in concrete material [85]. These waves can be used to measure the chloride content in a concrete sample non-destructively [86]. The principle of millimeter wave (MMW) is similar to near infrared and microwave spectroscopy. In this approach, a MMW is focused to a concrete sample through a prism. The reflected wave is then collected at a Gunn oscillator. This forms an attenuated total reflection (ATR)

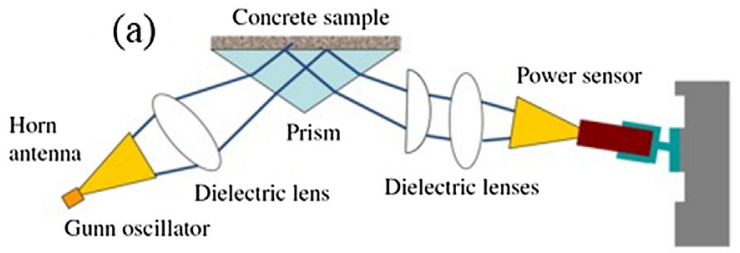

(b)

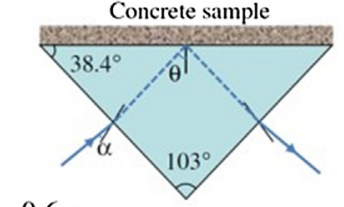

(c)

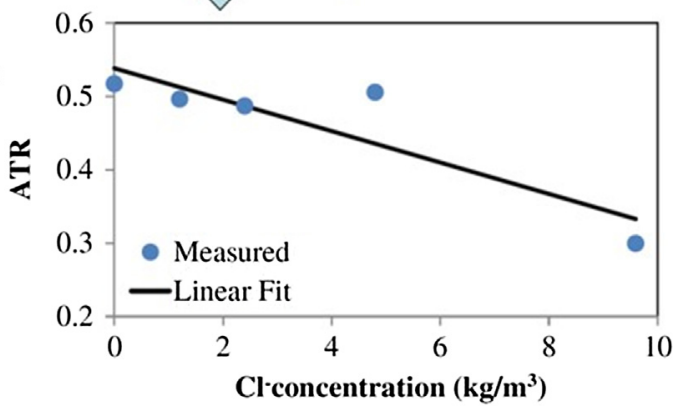

Fig. 8. (a) Schematic diagram of a millimeter wave attenuated total reflection (ATR) measurement setup. (b) Schematic diagram of a silicon prism used as total internal reflection medium. (c) ATR of samples with different $\mathrm{Cl}^{-}$concentrations [86].

measurement system to measure chloride ions in concrete. The refractive index of the reflecting medium should be larger than the concrete sample $[87,88]$. The MMW creates an evanescent wave at the interface of prism and sample, which penetrates into the sample.

The schematic of the experimental setup is shown in Fig. 8a and b. The MMW penetrates into the sample as defined by the penetration depth. When the material absorbs a MMW the beam loses its energy according to the sample dielectric properties. The ratio of the sample power and reference power gives the ATR. The measured ATR for various chloride ion concentrations is given in Fig. 8c. 
(a)

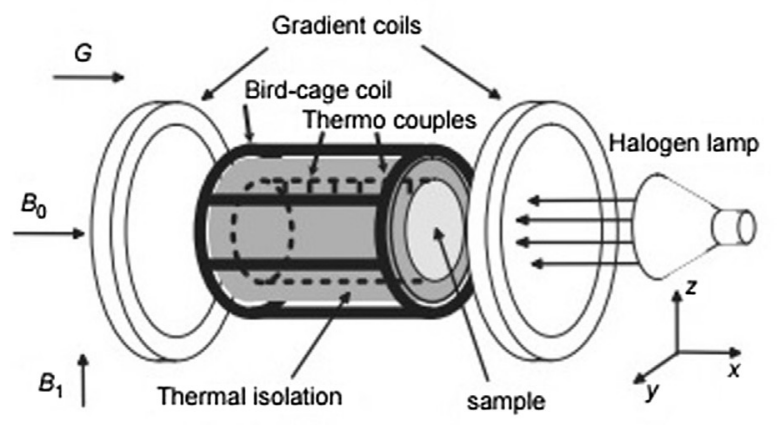

(b)

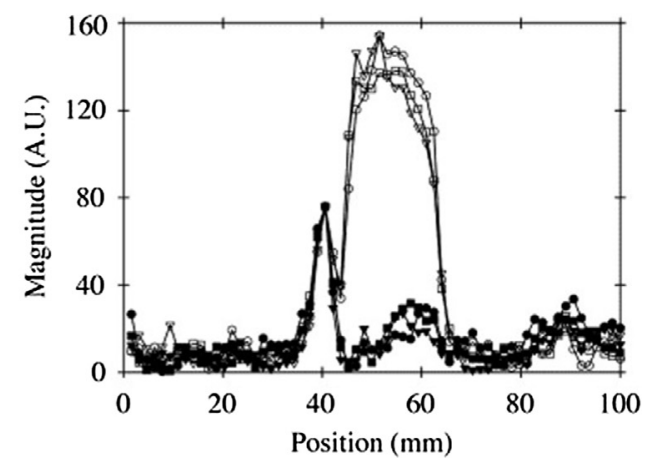

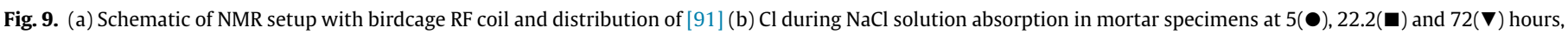
for $\mathrm{w} / \mathrm{c}=0.3$ and $0.6[92]$.

\subsubsection{Nuclear Magnetic Resonance (NMR)}

Nuclear magnetic resonance (NMR) is used for detailed analysis of concrete samples at the atomic scale. The NMR technique is able to determine the presence and concentration of different nuclei due to the magnetic behavior of the nuclei of atoms.

In this method, the non-zero spin nuclei of the material placed in a relatively big uniform magnetic field $B_{0}$ start to precess around the direction of $B_{0}$ with the specific frequency related to the gyromagnetic ratio of nuclei, called Larmor frequency $\omega_{0}$. Another radio frequency pulsed magnetic field, $B_{1}$, perpendicular to the static field is also utilized to generate small excitation in the sample and also receiving signal back from the sample $[89,90]$.

The possibility of detection of chloride with NMR in addition to the possibility of quasi-simultaneously measuring moisture, sodium and chloride makes NMR a suitable method to obtain chloride profiles as a function of time and position [93]. A typical NMR setup to detect chloride profiles is shown in Fig. 9a. The salt solution absorption profiles of $\mathrm{Cl}^{-}$for two different types of mortar at different time steps is shown in Fig. 9b. Here, the sample is moved by a step motor and the signal is collected in different crosssectional positions.

The poor limit of detection of chloride is an issue, which limits the detectable concentration range. One way to improve this limit is averaging over many recorded signals. However, the random noise level also increases by a factor of the square root of the number of scans but it is a considerable improvement in signal to noise ratio. Another way to improve the signal for chloride is increasing

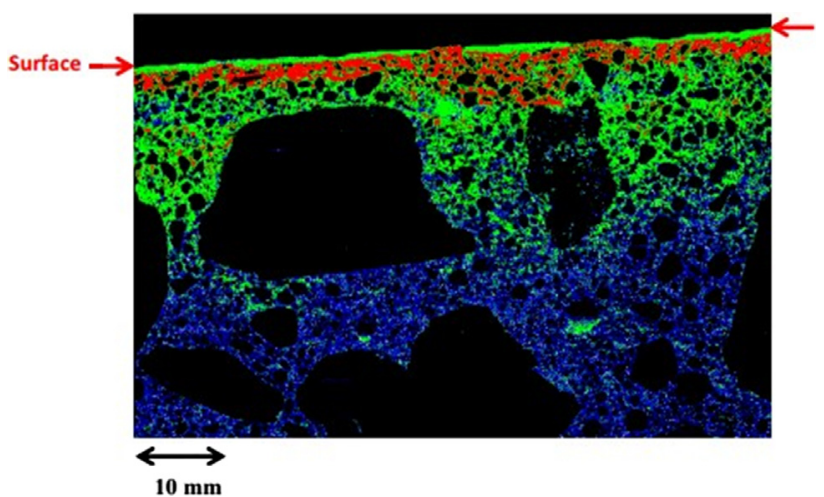

Fig. 10. The X-ray image of chloride gradient in cement paste where red, green and blue represent, highest, moderate and lowest concentrations [95]. (For interpretation of the references to colour in this figure legend, the reader is referred to the web version of this article.) the static magnetic field, $B_{0}$, or improving the $\mathrm{RF}$ coil. The signal to noise ratio (SNR) measurement is always required to find the lowest chloride concentration possible to detect [92].

\subsubsection{X-ray diffraction analysis}

$\mathrm{X}$-ray fluorescence is a commonly used method to analyze the chemical composition of inorganic materials. The X-ray beam produced by micro capillary optics excites the different atoms in the target material, the transient excited atoms decay to a lower energy state by emitting a characteristic X-ray, which is detected by an X-ray detector. Analysis of the results with data taken from highly controlled conditions determine the proportion of each element in the material. The quantitative X-ray analysis accuracy is highly dependent on homogeneity of the sample. Concrete is heterogeneous in all scales, so the specimen can be prepared in the form of a glass bead or a pellet of pressed powder. In case of grinding cement few more issues must be considered as the Xray intensity then is not only depended on chloride concentration but also on powder grain size, degree of compaction and chloride binding [94].

Sudbrink et al. studied the chloride gradient imaging by X-ray fluorescence analysis for cement paste, as shown in Fig. 10 [95]. This image is taken by moving the sample in a raster pattern under stationary X-ray radiation with a spacing of $50 \mu \mathrm{m}$.

\section{Discussion}

\subsection{Comparison of non-destructive techniques}

Each of the presented non-destructive techniques have their strengths and weaknesses. There are different factors, which influence the selection of these techniques for an application. These factors are listed in Table 1. The comparison among these techniques is based on the type of measured chloride, ease of embedding in concrete, long-term stability, robustness, ease of fabrication, cost effectiveness, and accuracy, see Table 1.

The electrochemical techniques such as potentiometry and chronopotentiometry are direct measurement techniques where the response is a direct function of the free chloride ions concentration, following fundamental principles i.e. Nernst law. The chemical stability in aggressive environments, ease of fabrication, cost effectiveness, and rigorous nature of $\mathrm{Ag} / \mathrm{AgCl}$ electrodes make them one of the mostly used techniques. However, the stability of the reference electrode $[39,51,96]$, cross-selectivity for $\mathrm{OH}^{-}$(or interference) and errors due to diffusion potentials $[37,97]$ restrict the long-term in-situ measurements for concrete [39]. The refer- 
Table 1

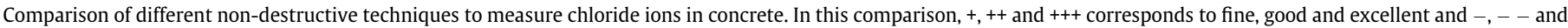
- - - corresponds to not good, bad and worse, respectively. Here N.A stands for "not available".

\begin{tabular}{|c|c|c|c|c|c|c|c|}
\hline Classification & Techniques & Type of measured chloride & $\begin{array}{l}\text { Ease of implementing } \\
\text { in concrete }+ \\
\text { portability }\end{array}$ & $\begin{array}{l}\text { Drift in } \\
\text { response } \\
\text { over time }\end{array}$ & Robustness & $\begin{array}{l}\text { Ease of } \\
\text { Fabrication }+ \text { cost } \\
\text { effectiveness }\end{array}$ & Selectivity \\
\hline \multirow[t]{3}{*}{ Electrochemical } & Potentiometric measurement & Free $\mathrm{Cl}^{-}$ & +++ & ++ & ++ & +++ & +++ \\
\hline & $\begin{array}{l}\text { Chrono-potentiometric } \\
\text { measurement }\end{array}$ & Free $\mathrm{Cl}^{-}$ & +++ & ++ & ++ & +++ & +++ \\
\hline & $\begin{array}{l}\text { Electrical resistivity and } \\
\text { impedance spectroscopy }\end{array}$ & $\mathrm{Cl}^{-}$diffusion coefficient & +++ & +++ & ++ & +++ & -- \\
\hline \multirow[t]{5}{*}{ Electromagnetic } & Fiber optic sensor & Free $\mathrm{Cl}^{-}$ & -- & -- & + & -- & ++ \\
\hline & $\begin{array}{l}\text { Laser breakdown } \\
\text { spectroscopy }\end{array}$ & Total chloride content & - & N.A. & - & - & - \\
\hline & $\begin{array}{l}\text { Near infrared, millimeter and } \\
\text { micro waves spectroscopy } \\
(\mathrm{MMW})\end{array}$ & $\begin{array}{l}\text { Free and Total chloride } \\
\text { content and diffusion } \\
\text { coefficient }\end{array}$ & + & N.A. & -- & -- & -- \\
\hline & $\begin{array}{l}\text { Nuclear magnetic resonance } \\
\text { (NMR) }\end{array}$ & $\begin{array}{l}\text { Free } \mathrm{Cl}^{-} \text {and diffusion } \\
\text { coefficient }\end{array}$ & --- & N.A. & + & --- & ++ \\
\hline & $\mathrm{X}$ rays analysis & Total chloride content & --- & N.A & + & --- & + \\
\hline
\end{tabular}

ence electrode needs to be calibrated to ensure steady potential, which is impractical for in-situ measurement [98]. The effect of $\mathrm{pH}$ is more pronounced when concentration of $\mathrm{OH}^{-}$is 10 times more than the $\left[\mathrm{Cl}^{-}\right]$. Then, the $\mathrm{Ag} / \mathrm{AgCl}$ electrode serves like a $\mathrm{pH}$ sensor i.e. sensitive to $\mathrm{OH}^{-}[37,60]$. Furthermore, the optimal sensitivity, i.e. $59 \mathrm{mV} /$ decade, implies that a potential deviation of 1 $\mathrm{mV}$ causes an error of ca. $4 \%$ in the determination of concentration[99]. The chronopotentiometric technique, on the other hand, has tunable sensitivity and better long-term stability due to its dynamic nature [58]. In the chronopotentiometric approach, a long-term stable reference electrode is not required, which makes it feasible for long-term measurement in concrete. However, the interference from $\mathrm{OH}^{-}$at high $\mathrm{pH}(12.5<\mathrm{pH}<13.5)$ still remains and restricts these measurements in concrete medium [100].

Electrical resistivity and impedance spectroscopy techniques are indirect techniques to measure potential chloride content, since they are not selective to chloride ion concentration but determine electrical properties. Electrical properties can be linked and interpreted in view of plausible $\mathrm{Cl}$ ions concentration. Furthermore, they are significantly influenced by other factors such as temperature, ionic composition, porosity, and moisture. Although these techniques are robust, cost effective, and easy to use, the non-sensitivity to chloride ions restrict their feasibility to directly measure $\mathrm{Cl}^{-}$concentration in concrete.

Electromagnetic techniques in general have bulky setups and poor sensitivity to $\mathrm{Cl}^{-}$. It is difficult to embed the electromagnetic based sensors in concrete. The optical sensor based on fiber optic material can be embedded in concrete but due to leaching of dyes (transducing element), it has poor long-term stability as compared to the electrochemical techniques [101,102]. Moreover, the development of an optical setup is complex and labor intensive. As compared to electrochemical techniques, the fiber optic sensors require extra protection by insulating the optical fibers from water, high alkalinity, and mechanical stresses.

In laser-induced breakdown spectroscopy (LIBS) the main issue lies with the low selectivity for chloride, the peaks of chloride ions are sometime not visible due to background noises. This is due to the low chloride content as compared to other elements in concrete. As compared to other contactless excitation techniques, LIBS has better portability and higher practical impact. This is evident from the number of studies performed using the LIBS technique. In case of the NMR technique, the biggest issue is the portability and the labor intensiveness. This also holds for X-ray analysis. Both of these techniques are highly accurate and are used for modelling and testing purposes. Unlike X-ray analysis, NMR requires cores from the structures and generates chloride diffusion profile along the core. The X-ray technique requires specialized sampling methodology and sample preparation. These techniques are mostly used for quality control of casting concrete in laboratory.

The other electromagnetic techniques, which uses an external excitation, such PGNA, MMV and GPR, generally lack sensitivity to chloride ions. These measurements are either based on changing the dielectric constant of the concrete due to chloride or exciting elements in concrete to detect elements signatures. Although these techniques are non-invasive, the complexity of the setup, labor intensiveness, non-selectivity for a specific element and expensiveness constraint these approaches in laboratory for detailed analysis. These techniques require a higher number of calibrations in different concrete conditions to counter the non-selectivity of chloride ions. These techniques have a potential of non-invasive, nondestructive and on-field analysis but so far, this is not the case.

Near infrared, millimeter (MMW) and microwaves spectroscopy are non-invasive electromagnetic techniques with better portability and implementation than other electromagnetic techniques. MMW technology is matured and well established, where high power MMW emitters and sensitive detectors such as a Gunn oscillator and a Schottky barrier diode, respectively, are easily accessible. The low sensitivity to chloride ions and ambient interference limits its feasibility. This method is sensitive to moisture and ionic composition of the concrete sample. These measurements are valid in controlled conditions with carefully obtained calibration curves. These techniques are capable of analyzing very large samples. They are helpful for qualitative analysis of chloride in concrete and to perform some initial quick investigation of structures.

\subsection{Strategies for in-situ chloride measurement}

In the previous section, the electrochemical and the electromagnetic techniques were compared and their pros and cons were briefly discussed. When applying these techniques in real life testing, the application, asset condition, measurement type (qualitative or quantitative) and the cost should be considered. Of course, it is not sensible to spend more resources on monitoring than on the maintenance of the structures. Depending on the requirement and the asset management of the structures, an efficient strategy should be outlined to measure chloride ions with the existing techniques. The outline of such strategy is given in Fig. 11.

The monitoring protocols are different for future structures as compared to existing structures. In case of existing structures, embedding the sensor by drilling cores and applying new concrete 
For existing structures

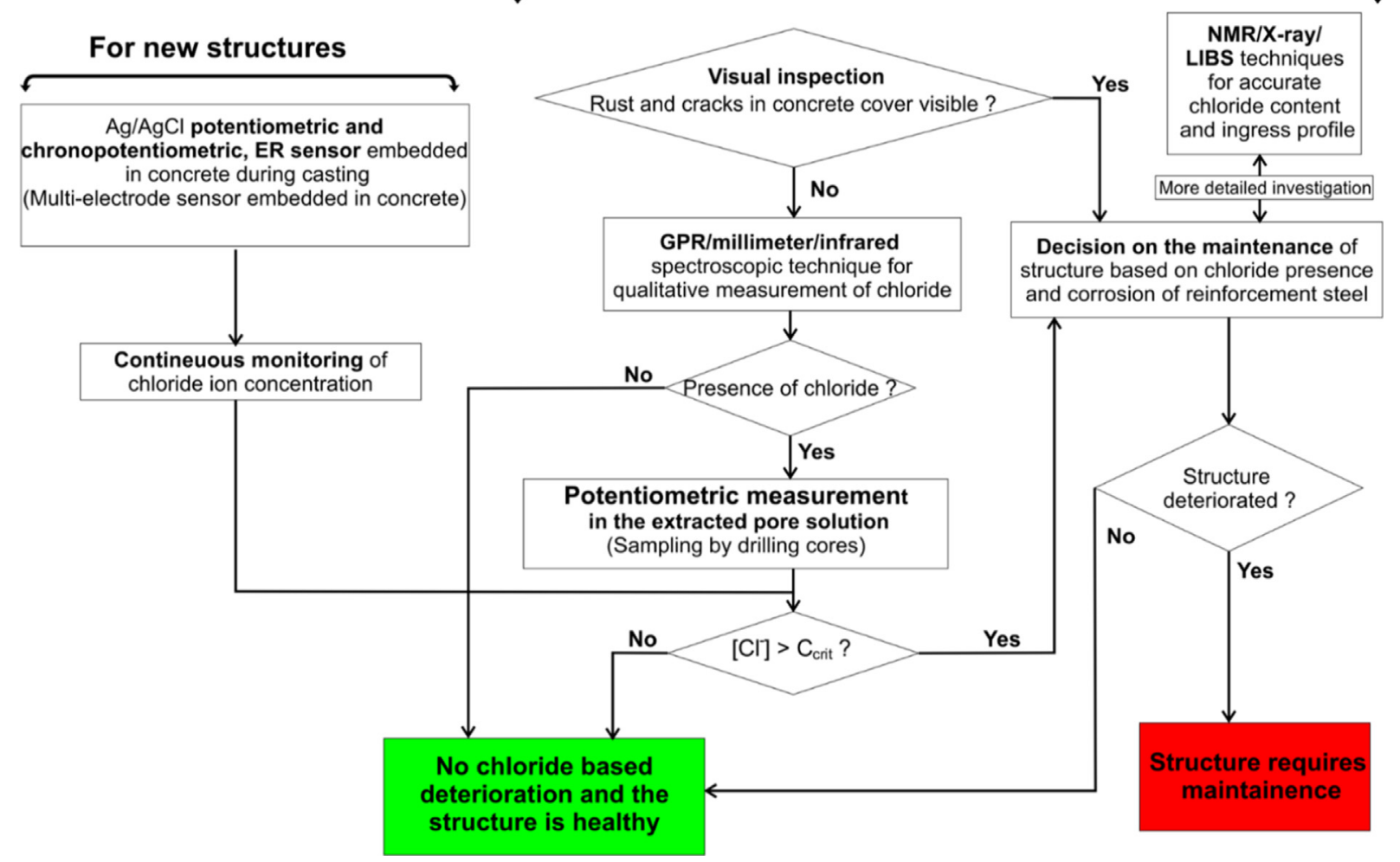

Fig. 11. The strategy for measuring chloride ion concentration in concrete using the existing techniques.

paste changes the actual condition of concrete around the sensor. This results in an erroneous signal, underestimating the $\mathrm{Cl}^{-}$concentration in the existing structure.

In existing structure, the first monitoring step is visual inspection. In the late propagation stage, when $\left[\mathrm{Cl}^{-}\right]$is higher than the critical concentration, $C_{c r i t}$, cracks, and huge corrosion products are visible on the concrete cover, depicting an acute deterioration. Such structures require maintenance straight away. In the absence of visual deterioration, the next step is the qualitative analysis using near-infrared/micro or millimeter wave spectroscopy. This will give a rough estimation of the $\left[\mathrm{Cl}^{-}\right]$. In general, electromagnetic techniques are expensive and labor intensive. Some techniques such as NMR, X-ray analysis and LIBS are accurate and more suitable for detailed investigation. Other techniques such as GPR, millimeter and microwave spectroscopy are suitable for a quick qualitative analysis of the chloride penetration in concrete. If there is no chloride or only low chloride concentrations, then the structure is healthy and does not require maintenance at this stage.

In the presence of $\mathrm{Cl}^{-}$in concrete, quantitative analysis is required to precisely determine the concentration. This can be done by the potentiometric measurement on the extracted pore solution (acquired by drilling cores of the sample). Now if the chloride concentration is below the critical content, the structure is healthy and has no chloride-based deterioration. If the concentration is above the critical value, the construction management should take the decision on the maintenance. In case of new structures for future construction the electrochemical approach with multiple sensors; potentiometric, chronopotentiometric and electrical resistivity sensor should be embedded in concrete and the chloride ion concentration should be monitored continuously to assess the deterioration due to chloride ions.

\section{Conclusions}

The presence of chloride ions is a major cause for the corrosion of steel reinforcement in concrete, resulting in its deterioration. The chloride ion concentration has been measured both in the laboratory and in the field. In the laboratory, it is measured to develop ingress models, able to determine the quality of concrete, whereas in the field, it determines the risk for deterioration of the existing structures. In field methods, the state of the art techniques are destructive and required the extraction of the concrete pore solution. For real time, reliable, and continuous monitoring of the chloride-based deterioration, a non-destructive measurement technique is needed. Over the last 20 years, several studies have been performed for non-destructive in-situ chloride ion measurement. These non-destructive approaches are divided into electrochemical and electromagnetic techniques.

For electrochemical techniques, potentiometry and chronopotentiometry, a $\mathrm{Ag} / \mathrm{AgCl}$ chloride ion selective electrode, has been used. In potentiometric measurements, which is a zero-current technique, the open circuit potential of an embedded $\mathrm{Ag} / \mathrm{AgCl}$ electrode is measured against a reference electrode. The stability of the reference electrode potential, low sensitivity, interference from other ions and the errors due to diffusion potential, limit the long-term use of this approach. Moreover, geometric positioning and temperature also affect the results. Chronopotentiometry is a dynamic measurement method not requiring a classical reference electrode. Similarly to potentiometry, the interference from hydroxide ions at high $\mathrm{pH}(\mathrm{pH}>12)$, limits the use of this technique in fresh concrete.

The electromagnetic techniques can be characterized into embedded and non-embedded techniques. In embedded 
techniques, a fiber optical sensor with optical transducer, sensitive to chloride is embedded in concrete. They are relatively inert to environmental factors, ion interference and geometric factors. Nevertheless, the lifetime of optical transducers, extra protection of fibers, and the bulky measurement setup restrict their use for long-term in-situ measurements. On the other hand, the nonembedded techniques with an external excitation, such as laser breakdown and near field spectroscopy, seem ideal due to the complete non-invasiveness and contactless nature. Nevertheless, these methods lack selectivity, portability, and local chloride ion measurement.

The assets management and construction industries are still struggling for a reliable and non-destructive technique to continuously monitor the structural integrity of concrete. Depending on the specific demands of the measurements, a strategy can be implemented employing the existing techniques. In this strategy, decision making on maintenance is based on the measurements from multiple approaches. Considering the severity and monitoring vs. maintenance costs, one approach or a combination of the available techniques can be used.

\section{Conflict of interest}

The authors declare no conflict of interest.

\section{Acknowledgments}

This work is a part of the STW project "Integral solution for sustainable construction (IS2C, http://is2c.nl/project-10968/)”. We are grateful to the STW Netherlands for their financial support.

\section{References}

[1] P.D. Cady, R.E. Weyers, Predicting service life of concrete bridge decks subject to reinforcement corrosion, in: Corrosion Forms and Control for Infrastructure, 1992, p. 328. vol. 1137.

[2] R.B. Polder, G. van der Wegen, K. van Breugel, K. van Breugel, G. Ye, Y. Yuan, Guideline for service life design of structural concrete with regard to chloride induced corrosion-the approach in the Netherlands, in 2nd International Symposium on Service Life Design for Infrastructures, 2010, pp. 265-272.

[3] F.P. Glasser, J. Marchand, E. Samson, Durability of concrete-degradation phenomena involving detrimental chemical reactions, Cem. Concr. Res. 38 (2008) 226-246.

[4] C. Andrade, M. Keddam, X. Nóvoa, M. Pérez, C. Rangel, H. Takenouti, Electrochemical behaviour of steel rebars in concrete: influence of environmental factors and cement chemistry, Electrochim. Acta 46 (2001) 3905-3912.

[5] C. Arya, N. Buenfeld, J. Newman, Factors influencing chloride-binding in concrete, Cem. Concr. Res. 20 (1990) 291-300.

[6] Q. Yuan, C. Shi, G. De Schutter, K. Audenaert, D. Deng, Chloride binding of cement-based materials subjected to external chloride environment-a review, Constr. Build. Mater. 23 (2009) 1-13.

[7] C. Page, K. Treadaway, Aspects of the Electrochemistry of Steel in Concrete, 1982.

[8] M. Montemor, A. Simoes, M. Ferreira, Chloride-induced corrosion on reinforcing steel: from the fundamentals to the monitoring techniques, Cem. Concr. Compos. 25 (2003) 491-502.

[9] K.Y. Ann, H.-W. Song, Chloride threshold level for corrosion of steel in concrete, Corros. Sci. 49 (2007) 4113-4133.

[10] L. Basheer, J. Kropp, D.J. Cleland, Assessment of the durability of concrete from its permeation properties: a review, Constr. Build. Mater. 15 (2001) 93-103.

[11] J.S. Volz, The Viability of Partially Post-tensioned Concrete Members in an Aggressive Environment, Including Cyclic Loading, ProQuest, 2008.

[12] H.-W. Song, C.-H. Lee, K.Y. Ann, Factors influencing chloride transport in concrete structures exposed to marine environments, Cem. Concr. Compos. 30 (2008) 113-121.

[13] K. Hong, R. Hooton, Effects of cyclic chloride exposure on penetration of concrete cover, Cem. Concr. Res. 29 (1999) 1379-1386.

[14] X. Shi, N. Xie, K. Fortune, J. Gong, Durability of steel reinforced concrete in chloride environments: an overview, Constr. Build. Mater. 30 (2012) 125138.

[15] W. McCarter, T. Chrisp, G. Starrs, A. Adamson, E. Owens, P. Basheer, et al., Developments in performance monitoring of concrete exposed to extreme environments, J. Infrastruct. Syst. 18 (2011) 167-175.
[16] E. Bastidas-Arteaga, F. Schoefs, Stochastic improvement of inspection and maintenance of corroding reinforced concrete structures placed in unsaturated environments, Eng. Struct. 41 (2012) 50-62.

[17] B.H. Oh, S.Y. Jang, Effects of material and environmental parameters on chloride penetration profiles in concrete structures, Cem. Concr. Res. 37 (2007) 47-53.

[18] M. Alonso, M. Sanchez, Analysis of the variability of chloride threshold values in the literature, Mater. Corros. 60 (2009) 631-637.

[19] M. Sanchez-Silva, G.-A. Klutke, D.V. Rosowsky, Life-cycle performance of structures subject to multiple deterioration mechanisms, Struct. Saf. 33 (2011) 206-217.

[20] M.A. Climent-Llorca, E. Viqueira-Pérez, M.M. López-Atalaya, Embeddable Ag/ $\mathrm{AgCl}$ sensors for in-situ monitoring chloride contents in concrete, Cem. Concr. Res. 26 (1996) 1157-1161.

[21] C. Atkins, J. Scantlebury, P. Nedwell, S. Blatch, Monitoring chloride concentrations in hardened cement pastes using ion selective electrodes, Cem. Concr. Res. 26 (1996) 319-324.

[22] M. Haque, O. Kayyali, Free and water soluble chloride in concrete, Cem. Concr. Res. 25 (1995) 531-542.

[23] G. Glass, Y. Wang, N. Buenfeld, An investigation of experimental methods used to determine free and total chloride contents, Cem. Concr. Res. 26 (1996) 1443-1449.

[24] T.C. Hansen, Physical structure of hardened cement paste. A classical approach, Mater. Struct. 19 (1986) 423-436.

[25] S. Munshi, A Mechanistic Approach For Predicting the Effect of Various Factors on Partitioning Between Free and Bound Chlorides in Concrete, University of Saskatchewan Saskatoon, 2009.

[26] G. Glass, N. Hassanein, N. Buenfeld, Neural network modelling of chloride binding, Mag. Concr. Res. 49 (1997) 323-335.

[27] C. Larsen, Chloride Binding in Concrete, Effect of Surrounding Environment and Concrete Composition (Dr. Thesis), NTNU, Trondheim, 1998, pp. 337340. vol. 95.

[28] J. Tritthart, Chloridinduzierte Betonstahlkorrosion (Chloride-induced corrosion of steel in concrete), in: Presented at the Schriftenreihe Strabenforschung des BMfwA, Vienna, 1988.

[29] K. Byfors, Chloride-initiated Reinforcement Corrosion, Swedish Cement and Concrete Research Institute, Stockholm, 1990.

[30] A. Suryavanshi, J. Scantlebury, S. Lyon, Corrosion of reinforcement steel embedded in high water-cement ratio concrete contaminated with chloride, Cem. Concr. Compos. 20 (1998) 263-281.

[31] A. Suryavanshi, J. Scantlebury, S. Lyon, The binding of chloride ions by sulphate resistant Portland cement, Cem. Concr. Res. 25 (1995) 581-592.

[32] V.S. Ramachandran, J.J. Beaudoin, Handbook of Analytical Techniques in Concrete Science and Technology: Principles, Techniques and Applications, Elsevier, 2000.

[33] U. Angst, Chloride Induced Reinforcement Corrosion in Concrete, Concept of Critical Chloride Content-Methods and Mechanisms, (Doctoral Thesis), vol. 113, pp. 978-982, 2011.

[34] U. Angst, B. Elsener, C.K. Larsen, Ø. Vennesland, Critical chloride content in reinforced concrete-a review, Cem. Concr. Res. 39 (2009) 1122-1138.

[35] A. C1152/C1152M-04e1,, Standard Test Method for Acid-Soluble Chloride in Mortar and Concrete, 2004.

[36] C. Alonso, M. Castellote, C. Andrade, Chloride threshold dependence of pitting potential of reinforcements, Electrochim. Acta 47 (2002) 3469-3481.

[37] U. Angst, B. Elsener, C.K. Larsen, Ø. Vennesland, Potentiometric determination of the chloride ion activity in cement based materials, J. Appl. Electrochem. 40 (2010) 561-573.

[38] A. Neville, Chloride attack of reinforced concrete: an overview, Mater. Struct. 28 (1995) 63-70.

[39] M. Torres-Luque, E. Bastidas-Arteaga, F. Schoefs, M. Sánchez-Silva, J.F. Osma, Non-destructive methods for measuring chloride ingress into concrete: stateof-the-art and future challenges, Constr. Build. Mater. 68 (2014) 68-81.

[40] J.L. Marriaga, P. Claisse, Effect of the non-linear membrane potential on the migration of ionic species in concrete, Electrochim. Acta 54 (2009) 2761-2769.

[41] E. Bastidas-Arteaga, Contribution for Sustainable Management of Reinforced Concrete Structures Subjected to Chloride Penetration, Université de Nantes, 2010.

[42] V.G. Papadakis, Effect of supplementary cementing materials on concrete resistance against carbonation and chloride ingress, Cem. Concr. Res. 30 (2000) 291-299.

[43] N. Nordtest, Build 208: Concrete, Hardened: Chloride Content by Volhard Titration, Nordtest (Ed.), 1996.

[44] M. Al-Hussaini, C. Sangha, B. Plunkett, P. Walden, The effect of chloride ion source on the free chloride ion percentages in OPC mortars, Cem. Concr. Res. 20 (1990) 739-745.

[45] J. Junsomboon, J. Jakmunee, Determination of chloride in admixtures and aggregates for cement by a simple flow injection potentiometric system, Talanta 76 (2008) 365-368.

[46] A. C1218,, Standard Test Method for Water-Soluble Chloride in Mortar and Concrete, American Society for Testing and Materials (ASTM), Philadelphia, PA, 2008.

[47] M. Castellote, C. Alonso, C. Andrade, P. Castro, M. Echeverría, Alkaline leaching method for the determination of the chloride content in the aqueous phase of hardened cementitious materials, Cem. Concr. Res. 31 (2001) 233-238.

[48] C. Arya, J. Newman, An assessment of four methods of determining the free chloride content of concrete, Mater. Struct. 23 (1990) 319-330. 
[49] S. Bonnet, F. SCHOEFS, J. Ricardo, M. Salta, Effect of error measurement of chloride profiles on reliability assessment, in: ICOSSAR'09, 2009.

[50] E. Sheils, A. O'Connor, D. Breysse, F. Schoefs, S. Yotte, Development of a twostage inspection process for the assessment of deteriorating infrastructure Reliab. Eng. Syst. Saf. 95 (2010) 182-194.

[51] B. Elsener, L. Zimmermann, H. Böhni, Non destructive determination of the free chloride content in cement based materials, Mater. Corros. 54 (2003) $440-446$.

[52] G. Duffó, S. Farina, C. Giordano, Characterization of solid embeddable reference electrodes for corrosion monitoring in reinforced concrete structures, Electrochim. Acta 54 (2009) 1010-1020.

[53] P. Hewlett, Lea's Chemistry of Cement and Concrete, ButterworthHeinemann, 2003.

[54] Y. Elakneswaran, T. Nawa, K. Kurumisawa, Electrokinetic potential of hydrated cement in relation to adsorption of chlorides, Cem. Concr. Res. 39 (2009) 340-344.

[55] G. De Vera, M. Climent, C. Antón, A. Hidalgo, C. Andrade, Determination of the selectivity coefficient of a chloride ion selective electrode in alkaline media simulating the cement paste pore solution, J. Electroanal. Chem. 639 (2010) 43-49.

[56] M. Molina, Zerstörungsfreie Erfassung der gelösten Chloride im Beton, Diss. Techn. Wiss ETH Zürich, Nr. 10315, 1993. Ref.: H. Böhni, Korref.: FH Wittmann, Korref.: B. Elsener, 1993.

[57] C. Atkins, M. Carter, J. Scantlebury, Sources of error in using silver/silver chloride electrodes to monitor chloride activity in concrete, Cem. Concr. Res. 31 (2001) 1207-1211.

[58] Y. Abbas, D.B. de Graaf, W. Olthuis, A. van den Berg, No more conventional reference electrode: transition time for determining chloride ion concentration, Anal. Chim. Acta 821 (2014) 81-88.

[59] E. Bakker, V. Bhakthavatsalam, K.L. Gemene, Beyond potentiometry: robust electrochemical ion sensor concepts in view of remote chemical sensing, Talanta 75 (2008) 629-635.

[60] Y. Abbas, W. Olthuis, A. van den Berg, A chronopotentiometric approach for measuring chloride ion concentration, Sensors Actuators B: Chemical 188 (2013) 433-439.

[61] A.J. Bard, L.R. Faulkner, Electrochemical Methods: Fundamentals and Applications, second ed., Wiley and Sons, Hoboken, 2001.

[62] F. Rajabipour, J. Weiss, J.D. Shane, T.O. Mason, S.P. Shah, Procedure to interpret electrical conductivity measurements in cover concrete during rewetting, J. Mater. Civ. Eng. 17 (2005) 586-594.

[63] C. Larsen, E. Sellevold, F. Askeland, J. Østvik, O. Vennesland, Electrical resistivity of concrete part II: Influence of moisture content and temperature, in: 2nd International symposium on advances in concrete through science and engineering. Quebec, Canada, 2006.

[64] R.B. Polder, Test methods for on site measurement of resistivity of concrete-a RILEM TC-154 technical recommendation, Constr. Build. Mater. 15 (2001) $125-131$.

[65] D. McPolin, P. Basheer, A. Long, K. Grattan, T. Sun, Obtaining progressive chloride profiles in cementitious materials, Constr. Build. Mater. 19 (2005) 666-673.

[66] P. Basheer, P. Gilleece, A. Long, W. Mc Carter, Monitoring electrical resistance of concretes containing alternative cementitious materials to assess their resistance to chloride penetration, Cem. Concr. Compos. 24 (2002) 437-449.

[67] W.J. McCarter, G. Starrs, S. Kandasami, R. Jones, M. Chrisp, Electrode configurations for resistivity measurements on concrete, ACI Mater. J. 106 (2009).

[68] O. Sengul, Use of electrical resistivity as an indicator for durability, Constr. Build. Mater. 73 (2014) 434-441.

[69] R. Vedalakshmi, R.R. Devi, B. Emmanuel, N. Palaniswamy, Determination of diffusion coefficient of chloride in concrete: an electrochemical impedance spectroscopic approach, Mater. Struct. 41 (2008) 1315-1326.

[70] R. Vedalakshmi, V. Saraswathy, H.-W. Song, N. Palaniswamy, Determination of diffusion coefficient of chloride in concrete using Warburg diffusion coefficient, Corros. Sci. 51 (2009) 1299-1307.

[71] H.-N. Li, D.-S. Li, G.-B. Song, Recent applications of fiber optic sensors to health monitoring in civil engineering, Eng. Struct. 26 (2004) 1647-1657.

[72] O.S. Wolfbeis, Fiber-optic chemical sensors and biosensors, Anal. Chem. 80 (2008) 4269-4283.

[73] J.-L. Tang, J.-N. Wang, Measurement of chloride-ion concentration with longperiod grating technology, Smart Mater. Struct. 16 (2007) 665.

[74] D.O. McPolin, P. Basheer, A.E. Long, W. Xie, T. Sun, K.T. Grattan, Development and longer term in situ evaluation of fiber-optic sensors for monitoring of structural concrete, IEEE Sensors J. 9 (2009) 1537-1545.

[75] C. Merzbacher, A. Kersey, E. Friebele, Fiber optic sensors in concrete structures: a review, Smart Mater. Struct. 5 (1996) 196.
[76] P.L. Fuhr, D.R. Huston, B. MacCraith, Embedded fiber optic sensors for bridge deck chloride penetration measurement, Opt. Eng. 37 (1998) 1221-1228.

[77] F. Laferrière, D. Inaudi, P. Kronenberg, I.F. Smith, A new system for early chloride detection in concrete, Smart Mater. Struct. 17 (2008) 045017.

[78] C.C.C. Lam, R. Mandamparambil, T. Sun, K.T. Grattan, S.V. Nanukuttan, S.E Taylor, et al., Optical fiber refractive index sensor for chloride ion monitoring, IEEE Sensors J. 9 (2009) 525-532.

[79] G. Wilsch, F. Weritz, D. Schaurich, H. Wiggenhauser, Determination of chloride content in concrete structures with laser-induced breakdown spectroscopy, Constr. Build. Mater. 19 (2005) 724-730.

[80] C.D. Gehlen, E. Wiens, R. Noll, G. Wilsch, K. Reichling, Chlorine detection in cement with laser-induced breakdown spectroscopy in the infrared and ultraviolet spectral range, Spectrochim. Acta, Part B 64 (2009) 1135-1140.

[81] M. Gondal, Z. Yamani, T. Hussain, O. Al-Amoudi, Determination of chloride content in different types of cement using laser-induced breakdown spectroscopy, Spectrosc. Lett. 42 (2009) 171-177.

[82] B. Savija, J. Pacheco Farias, E. Schlangen, S. Millar, T. Eichler, G. Wilsch, Chloride ingress in cracked concrete studied using Laser Induced Breakdown Spectroscopy, in: AMS 14: Proceedings of the 1st Ageing of Materials \& Structures Conference, Delft, The Netherlands, 26-28 May 2014, 2014.

[83] B. Šavija, E. Schlangen, J. Pacheco, S. Millar, T. Eichler, G. Wilsch, Chloride ingress in cracked concrete: a laser induced breakdown spectroscopy (LIBS) study, J. Adv. Concr. Technol. 12 (2014) 425-442.

[84] G. Wilsch, D. Schaurich, F. Weritz, H. Wiggenhauser, Laser-induced breakdown spectroscopy for on-site determination of chloride in concrete, Proc. NDT-CE, Federal Institute for Materials Research and Testing (BAM), Berlin, Germany, 2003. vol. 3.

[85] A. Robert, Dielectric permittivity of concrete between $50 \mathrm{MHz}$ and $1 \mathrm{GHz}$ and GPR measurements for building materials evaluation, J. Appl. Geophys. 40 (1998) 89-94.

[86] S.R. Tripathi, H. Inoue, T. Hasegawa, K. Kawase, Non-destructive inspection of chloride ion in concrete structures using attenuated total reflection of millimeter waves, J. Infrared Millimeter Terahertz Waves 34 (2013) 181-186.

[87] M. Kohri, T. Ueda, H. Mizuguchi, Application of a near-infrared spectroscopic technique to estimate the chloride ion content in mortar deteriorated by chloride attack and carbonation, J. Adv. Concr. Technol. 8 (2010) 15-25.

[88] S.R. Tripathi, H. Ogura, H. Inoue, T. Hasegawa, K. Takeya, K. Kawase, Measurement of chloride ion concentration in concrete structures using terahertz time domain spectroscopy (THz-TDS), Corros. Sci. 62 (2012) 5-10.

[89] C.P. Slichter, Principles of magnetic resonance vol. 1, Springer Science \& Business Media, 2013

[90] H. Yun, M.E. Patton, J.H. Garrett, G.K. Fedder, K.M. Frederick, J.-J. Hsu, et al., Detection of free chloride in concrete by NMR, Cem. Concr. Res. 34 (2004) 379-390.

[91] G. Van Der Heijden, R. Van Bijnen, L. Pel, H. Huinink, Moisture transport in heated concrete, as studied by NMR, and its consequences for fire spalling, Cem. Concr. Res. 37 (2007) 894-901.

[92] F. de J. Cano, T. Bremner, R. McGregor, B. Balcom, Magnetic resonance imaging of $1 \mathrm{H}, 23 \mathrm{Na}$, and $35 \mathrm{Cl}$ penetration in Portland cement mortar, Cem. Concr. Res. 32 (2002) 1067-1070.

[93] J. Petković, H. Huinink, L. Pel, K. Kopinga, R. van Hees, Moisture and salt transport in three-layer plaster/substrate systems, Constr. Build. Mater. 24 (2010) 118-127.

[94] E. Proverbio, F. Carassiti, Evaluation of chloride content in concrete by X-ray fluorescence, Cem. Concr. Res. 27 (1997) 1213-1223.

[95] B. Sudbrink, T. Ley, J.M. Davis, Applications of micro X-ray fluorescence in concrete, Microsc. Microanal. 18 (2012) 952-953.

[96] S. Makarychev-Mikhailov, A. Shvarev, E. Bakker, Pulstrodes: triple pulse control of potentiometric sensors, J. Am. Chem. Soc. 126 (2004) 1054810549.

[97] U. Angst, Ø. Vennesland, R. Myrdal, Diffusion potentials as source of error in electrochemical measurements in concrete, Mater. Struct. 42 (2009) 365375.

[98] W.J. McCarter, Ø. Vennesland, Sensor systems for use in reinforced concrete structures, Constr. Build. Mater. 18 (2004) 351-358.

[99] U. Angst, Ø. Vennesland, Detecting critical chloride content in concrete using embedded ion selective electrodes-effect of liquid junction and membrane potentials, Mater. Corros. 60 (2009) 638-643.

[100] P. Mehta, P. Monteiro, Microstructure and properties of hardened concrete, Concr. Microstr. Proper. Mater. (2006) 41-80.

[101] G. Liebsch, I. Klimant, C. Krause, O.S. Wolfbeis, Fluorescent imaging of pH with optical sensors using time domain dual lifetime referencing. Anal. Chem. 73 (2001) 4354-4363.

[102] C. McDonagh, C.S. Burke, B.D. MacCraith, Optical chemical sensors, Chem. Rev. 108 (2008) 400-422. 